\title{
50 ANOS DO LIVRO KNOWLEDGE AND CONTROL: NEW DIRECTION FOR SOCIOLOGY OF EDUCATION, ENTREVISTA COM MICHAEL YOUNG
}

50 YEARS OF THE BOOK KNOWLEDGE AND CONTROL: NEW DIRECTION FOR SOCIOLOGY OF EDUCATION, INTERVIEW WITH MICHAEL YOUNG

50 AÑOS DEL LIBRO KNOWLEDGE AND CONTROL: NEW DIRECTION FOR SOCIOLOGY OF EDUCATION, ENTREVISTA CON MICHAEL YOUNG

\author{
Marcelo Pinheiro Cigales ${ }^{1}$ \\ Amurabi Pereira de Oliveira ${ }^{2}$ \\ Diego Greinert de Oliveira ${ }^{3}$
}

\section{Apresentação}

Q

m 1971, o professor Michael Young organizou um livro que marcaria uma geração de pesquisadores da Sociologia da Educação, inaugurando o que se convencionou chamar desde então Nova Sociologia da Educação (NSE). Em Knowledge and Control: New Direction for the Sociology of Education (sem tradução para a língua portuguesa), Young, em conjunto com outros autores, como Pierre Bourdieu, Basil Bernstein, Geoffrey Esland e Neil Keddie, propõe uma discussão para além de questões centradas unicamente em um currículo técnico, cujo objetivo era quase exclusivamente refletir sobre os melhores métodos e técnicas para garantir uma eficiência na organização curricular e de ensino. Assim, a NSE introduz uma forma de analisar o currículo na sua origem, direcionando a reflexão sociológica sobre as escolhas, os jogos políticos e os agentes do campo educacional que definiam o quê deve ser ensinado e como.

Moreira e Silva (2002) apontam a originalidade da NSE e como ela inaugura uma reflexão sociológica original acerca do currículo. Sua difusão no mundo anglófono ocorre de modo relativamente rápido, impactando, posteriormente, outras tradições sociológicas em educação.

É certo que, ao longo das décadas, o próprio autor reformula algumas questões em relação a essa perspectiva, trazendo a discussão para o que denominou conhecimento poderoso, um conhecimento que permite aos alunos compreenderem o mundo em que vivem nas suas relações mais amplas. Dessa forma, a questão que os sistemas de ensino e as instituições escolares devem ter em perspectiva é se o currículo seria um meio de alcançar esse conhecimento poderoso, conhecimento esse disponibilizado por meio da educação escolar e que poderia proporcionar às crianças de lares desfavorecidos um desenvolvimento intelectual para além de suas circunstâncias locais e particulares (YOUNG, 2007).

No Brasil, a obra de Young passou a ganhar maior notoriedade a partir da segunda metade nos anos de 1980, quando são traduzidos seus primeiros trabalhos no país, como os artigos "A Propósito de uma Sociologia Crítica de Educação" (1986) e "Currículo e Democracia: Lições de uma Crítica à 'Nova Sociologia

1.Universidade de Brasília - Brasília (DF), Brasil. E-mail: marcelo.cigales@unb.br

2.Universidade Federal de Santa Catarina - Florianópolis (SC), Brasil. E-mail: amurabi1986@gmail.com

3.Universidade Federal de Santa Catarina - Florianópolis (SC), Brasil. E-mail: diego_pnd@hotmail.com

Editor de Seção: Ivany Rodrigues Pino 
da Educação"' (1989). A partir dos anos de 1990, também passam a circular sínteses produzidas por alguns de seus intérpretes brasileiros (SILVA, 1992), assim como traduções de autores estrangeiros, por exemplo JeanClaude Forquin, em Escola e Cultura: as Bases Sociais e Epistemológicas do Conhecimento Escolar (1993). Esse processo ocorreu de forma concomitante à autonomização do campo de estudos do currículo no Brasil, com o surgimento de programas, linhas de pesquisa e periódicos especializados nesse período.

Pensar o currículo na perspectiva da Sociologia da Educação e da Nova Sociologia da Educação, inaugurada pela obra de Michael Young, torna-se ainda mais pertinente quando estamos em processo de transformação curricular nas esferas municipal, estadual e federal, articulada pela Base Nacional Comum Curricular (BNCC) para o Ensino Médio, aprovada em 2018, e pela Reforma do Ensino Médio (2017), que impulsiona as unidades federativas a pensar seus currículos, seus sentidos e suas identidades. Tal discussão nos remete aos aspectos da teoria de Young que ele mesmo passou a rever em um período mais recente, pois, a despeito de reconhecer que as escolas em sociedades capitalistas reproduzem a classe social e outras desigualdades, o autor reconhece que “[...] que o papel das escolas e do currículo centrado em disciplinas é mais complexo do que apenas manter desigualdades” (YOUNG, 2011, p. 617).

Posto isso, cabe ainda destacar que esta entrevista perpassa uma série de pontos que partem da formação profissional e acadêmica de Young, a influência e parceria com Basil Bernstein, o contexto de surgimento da obra Knowledge and Control: New Directions in Sociology of Education e sua virada teórica, "de uma combinação da fenomenologia com o marxismo" para uma abordagem "de forma crítica ao estruturalismo", compreendida como "realismo social (social realism)". Por fim, Young nos apresenta as disputas nas formulações curriculares na Inglaterra, incluindo os ataques às Ciências Sociais e os desafios de uma agenda de pesquisas relacionadas à Sociologia da Educação e à questão curricular.

Assim, os apontamentos contidos nesta entrevista com Michel Young, professor emérito do Instituto de Educação da Universidade de Londres, auxiliarão leitores(as) e pesquisadores(as) do currículo a ter um olhar mais amplo e profundo acerca das proposições e perspectivas teóricas do autor e da obra em questão, a qual, em 2021, completa cinquenta anos desde sua primeira edição.

A nós, cabe os agradecimentos ao professor Michael Young e à sua gentileza em responder aos nossos questionamentos. Uma boa leitura!

\section{Entrevista}

\section{Professor Young, você poderia nos contar sobre sua formação educacional e sua experiência profissional, explicando como entrou no campo da Sociologia da Educação?}

Michael Young: Estudei Ciências Naturais na Universidade de Cambridge e, depois de um ano trabalhando na Shell em vendas de plásticos, tornei-me professor de ciências do Ensino Médio. À noite, estudei uma segunda graduação em Sociologia e me formei cinco anos depois, com um bacharelado, pela Universidade de Londres. Tirei um ano (1966-1967) sem ensinar para estudar em tempo integral para um mestrado em Sociologia na Universidade de Essex. Tive a sorte de ter Basil Bernstein (1924-2000) como meu tutor, o que me levou a me candidatar e a ser nomeado professor assistente de Sociologia da Educação no Instituto de Educação da Universidade de Londres, onde Bernstein era professor titular. Continuei a focar na Sociologia do Currículo, que iniciei na minha dissertação de mestrado. Isso levou a várias apresentações de conferências não publicadas e ao meu primeiro livro Knowledge and Control (Conhecimento e Controle, ainda em tradução para o português). 
Naquela época, havia o estabelecimento de um campo adequadamente autônomo do que viria a ser conhecido como "Sociologia do Currículo"? Como o senhor chegou especificamente a esse tópico?

Michael Young: Basil Bernstein foi uma grande influência para mim na escolha do meu tema de dissertação. Até então, os sociólogos eram poucos em número e, na Inglaterra, o trabalho deles surgiu de estudos demográficos que demonstravam o poderoso papel da classe social na determinação de oportunidades educacionais e de oportunidades de vida. Quando me tornei professor assistente, Bernstein procurava maneiras de mover a Sociologia da Educação para além do foco “distributivo". Seus trabalhos no início dos anos 1970 começaram a problematizar o "o que" da Educação e isso levou a um foco no currículo, que ele desenvolveu em seu artigo, bem conhecido, no meu livro The Classification and Framing of Educational Knowledge (A Classificação e o Enquadramento do Conhecimento Educacional, ainda sem tradução para o português).

\section{O senhor poderia nos dizer como surgiu a ideia do livro Knowledge and Control (1971)? Em sua avaliação, qual é a pontualidade das questões levantadas na época quase cinquenta anos depois?}

Michael Young: Na prática, surgiu da Conferência Anual da British Sociological Association (BSA; do inglês, Associação Britânica de Sociologia), em 1970; seu tema era Educação e Bernstein e eu estávamos envolvidos em seu planejamento. Ambos apresentamos artigos. Também combinamos que Pierre Bourdieu, pouco conhecido no Reino Unido à época, fosse convidado. A ideia para o livro foi de Bernstein em uma reunião, após a conferência, que ele e eu tivemos com Bourdieu. Todos nós sentimos que era uma oportunidade de reunir algumas das ideias discutidas na Conferência para uma ampliação do campo da Sociologia da Educação. Foi Bernstein quem sugeriu que eu editasse um livro e encontrou uma editora. O resultado, um ano depois, foi Knowledge and Control: New Directions in Sociology of Education.

Teoricamente, era uma coleção altamente eclética. Eu estava no estágio inicial da minha carreira acadêmica e o que a uniu, pelo menos para mim, foi a relação entre poder e conhecimento e como isso era expressado na escolaridade e no currículo. Foi essa relação que se mostrou "atemporal” e que não apenas moldou a Sociologia da Educação desde então, mas tem sido um tema subjacente às mudanças na política curricular em muitos países. Acho que o legado mais importante que restou foi que a distribuição de oportunidades educacionais e suas consequências para a igualdade e a justiça social nunca podem ser entendidas pela Educação como apenas um "bem" quantificável, um salário maior; sempre envolve julgamentos éticos, políticos e epistemológicos.

\section{Knowledge and Control contou com a participação de autores conhecidos no campo da Sociologia da Educação, como Bourdieu e Bernstein. Como participaram esses colegas? É possível apontar como seu trabalho difere da abordagem desenvolvida por esses outros dois sociólogos?}

Michael Young: A resposta para a primeira pergunta é simples. Bernstein, já conhecido por seus estudos sociolinguísticos, concordou que seu discurso na Conferência da Associação Britânica de Sociologia (The Classification and Framing of Educational Knowledge) poderia ser incluído, e eu escrevi a Bourdieu a fim de obter permissão para incluir seus únicos documentos que na época haviam sido traduzidos para inglês. Quanto à diferença entre o meu trabalho e o deles, tenho apenas o espaço para ser breve acerca de uma pergunta sobre a qual estou iniciando um livro inteiro. A divisão fundamental entre mim, Bourdieu e Bernstein era, originalmente, que ambos eram estruturalistas e, com minha combinação de fenomenologia 
e marxismo, adotei uma posição antiestruturalista, ou construtivista social. Recentemente - especialmente em meu terceiro livro, Bringing Knowledge Back (publicado em 2007, sem tradução para o português) - modifiquei minha posição e agora apoio uma forma crítica de estruturalismo, que chamamos realismo social. Eu respeito o trabalho de Bourdieu, mas nunca fiquei feliz com seu conceito-chave de "campo". Não é capaz, na minha opinião, de lidar com as questões socioepistêmicas em torno do conhecimento que um sociólogo enfrenta ao abordar o currículo como uma produção social. Bernstein e eu nunca fomos reconciliados durante sua vida; no entanto, minha redescoberta da importância de Durkheim me deu um novo respeito por seu trabalho, que acredito ter desempenhado um papel importante, se não sempre reconhecido, na Sociologia da Educação e ainda desempenha.

\section{Até que ponto sua noção de "conhecimento poderoso" se aproxima ou se distancia da "pedagogia racional" proposta por Bourdieu e Passeron em Os Herdeiros?}

Michael Young: Nunca considerei a contradição no trabalho de Bourdieu - entre desiludir os leitores da possibilidade de Educação como fonte de mudança social radical e usar o próprio prestígio como professor para fazer exatamente isso - útil ou convincente. Penso que o conceito de Bernstein de "dispositivo pedagógico" é muito mais útil.

Ao longo de sua trajetória de pesquisa, o senhor construiu um argumento que, em Knowledge and Control, entendia o currículo como um espaço de luta e reprodução social, para uma perspectiva que reconhece a relevância de um "conhecimento poderoso", o qual não pode servir apenas aos “poderosos”. Portanto, há uma mudança abrangente nessa direção. Poderíamos dizer que o senhor mudou de uma perspectiva analítico-descritiva para uma perspectiva analítico-proposicional?

Michael Young: Isso não está correto. Em Knowledge and Control, vi o currículo como mais bem-analisado em termos do que descrevi mais recentemente como "conhecimento dos poderosos". Assim, minha posição era de total criticismo ao currículo, sempre expressando os interesses daqueles que queriam manter seu poder. Minha posição revisada adota uma postura realista social, que reconhece uma realidade física e social material além de qualquer coisa que "construímos". Em outras palavras, o conhecimento é "socialmente construído", mas, como Marx colocou, "não nas circunstâncias de nossa própria escolha”. Conclui-se que, ao estabelecer a Educação formal, não há alternativa para reconhecer a realidade de que existem "comunidades de pesquisadores" que buscam e, no processo, alcançam o que há de melhor na verdade que temos.

Nesse processo, a possibilidade de perturbar e também reproduzir a ordem social é sempre possível. Assim, a fonte de emancipação que está no cerne do trabalho de alguém como Paulo Freire está no próprio processo de criação de um currículo e, no termo que tenho usado recentemente, conhecimento poderoso. Acredito que essa é uma abordagem um pouco diferente da sua de analítico-descritivo para analítico-proposicional.

Professor, há um movimento de retorno aos currículos, apreciação do currículo e das disciplinas escolares. É uma forma de crítica a uma Pedagogia centrada no aluno? É possível advogar um currículo focado nas disciplinas escolares, mas também dialogar com as experiências concretas que os alunos trazem para a escola? Em caso afirmativo, como?

Michael Young: O que foi conhecido como o "retorno ao conhecimento" é uma crítica direta ao aprendizado e à Pedagogia centrados no aluno e eles não são, na minha opinião, reconciliáveis. No entanto, o "retorno 
ao conhecimento" propõe a Pedagogia como um diálogo entre o conhecimento baseado na disciplina e a experiência do aluno com base no seu conhecimento cotidiano.

Os professores se deparam com o que foi chamado de "ruptura" da consciência do aluno, que, envolvido com o conhecimento escolar, cria com o conhecimento que os alunos trazem para a escola. A principal alternativa pedagógica e curricular é a noção de desenvolver uma "relação com o conhecimento" pelo aluno, não sua memorização. Esse é um conceito que está sendo desenvolvido por Bernard Charlot no Brasil, em sua pesquisa na Universidade Federal de Sergipe. O trabalho nesse sentido está em um estágio inicial de desenvolvimento, que mal começou na tradição inglesa da Sociologia da Educação. Está muito no centro do meu trabalho atual com professores no Instituto de Educação da University College of London, em Londres.

Poderíamos dizer que é um fenômeno relativamente amplo que o ataque às Ciências Sociais nos currículos escolares venha ocorrendo em diferentes países de diferentes maneiras. Na sua opinião, que "conhecimento poderoso" as Ciências Sociais, como disciplinas escolares, podem oferecer às nossas gerações nos países do Norte e do Sul globais?

Michael Young: A questão das Ciências Sociais no currículo escolar está de fora da minha área de especialização e, até onde eu sei, foi objeto de muito pouca pesquisa; portanto, o que escrevo é uma opinião mais pessoal e menos resultante de qualquer investigação sistemática. Espero que minhas observações sejam tratadas com mais cautela que o usual.

A Sociologia tem sido amplamente oferecida nos currículos do Ensino Médio na Inglaterra, mas agora está "em retirada". Isso é, parcialmente, consequência das pressões políticas de uma década de governos conservadores que se opuseram a ela por não cumprir seus critérios de conhecimento acadêmico. Também é, parcialmente, consequência de um ceticismo mais amplo sobre se a introdução da Sociologia para estudantes que possuem conhecimentos limitados nas histórias social, econômica e cultural é justificada educacionalmente. Isso pode levar, como é evidenciado em livros didáticos e scripts de exame, a uma superficialidade no que os alunos escrevem, não pela falta de capacidade intelectual, mas pela falta de tempo para testar ideias sociológicas abstratas em suas experiências e em exemplos de estudos empíricos em geral.

Notoriamente, esses ataques também se relacionam a disputas que ocorrem no currículo escolar, entendido como lugar de disputas entre diferentes concepções de mundo. Pensando no cenário contemporâneo, que configurações e disputas curriculares você observa hoje na Inglaterra?

Michael Young: Vale a pena fazer dois tipos de comentário em resposta a esta pergunta. O primeiro é que muitas das disputas mais importantes são específicas para as diferentes disciplinas e, portanto, requerem formas interdisciplinares de investigação, que ainda são raras. Isso também significa que, como sociólogo, embora eu tenha um conhecimento limitado sobre assuntos individuais, não tenho o conhecimento necessário sobre o conteúdo detalhado - específico para tomar decisões.

As pressões enfrentadas pelos professores surgem da extensão em que o governo interpreta os padrões e a qualidade em termos de aumentar a estipulação de conteúdo específico. Isso resulta nas restrições inevitáveis do horário escolar e em uma ênfase na memorização e no tratamento do conhecimento em termos de "bits de informação" a ser "reproduzidos" nos exames. Vale a pena mencionar duas outras tendências não relacionadas: a tendência ao genérico e a maior ênfase em testar quais líderes levam a um estreitamento 
do currículo, especialmente para aqueles que acham difícil o aprendizado. A tendência ao genérico é uma resposta ao aumento de novos conhecimentos e ao estreitamento do conteúdo das disciplinas, resultado de regimes internacionais de testes, como a avaliação PISA da OCDE, que deve ser aplicável a uma gama cada vez mais diversificada de países - as ciências individuais são substituídas pela alfabetização científica, a matemática pela numeracia e a literatura pelo letramento. A ênfase nos testes impacta particularmente na fase da educação primária, pois as escolas tendem a se concentrar em matemática, ciências e inglês, não tendo tempo para se concentrar nas ciências humanas e nas artes. Algo que vale a pena mencionar, que é conseqüência não intencional da "virada do conhecimento" nos currículos, refere-se a um ponto anterior sobre como acessar o conhecimento escolar que envolve uma ruptura com a experiência cotidiana dos alunos. Isso reflete uma resposta exagerada às políticas centradas no aluno da década anterior. Sua ênfase em mais conteúdo de conhecimento pode minimizar a extensão em que a aquisição de conhecimento envolve o engajamento ativo dos alunos.

\section{Quais são os principais desafios da Sociologia do Currículo hoje em termos da agenda de pesquisa?}

Michael Young: É importante começar uma resposta a essa pergunta enfatizando o papel relativamente marginal da "Sociologia do Currículo". A Sociologia, pelo menos fora dos EUA, tem uma preocupação longa e contínua com a justiça educacional. Isso foi expresso nas décadas de 1960 e 1970 por seu foco dominante na classe social. No entanto, isso se expandiu significativamente para incluir gênero, raça e deficiência e, mais recentemente, estudos de sexualidade. Não é que esses focos especializados não estejam preocupados com o currículo; é que eles se concentram em formas específicas de crítica e identificação de negligência e discriminação em seus assuntos. Outro desafio enfrentado pela Sociologia do Currículo é que muitos estudantes acham difícil demais abstrair, além do excesso de jargão. Isso ocorre, em parte, porque a palavra conhecimento em si é um dado adquirido e possui significados muito diferentes, dependendo do contexto conhecimento do nome de um primo ou rua próxima e conhecimento da equação da relatividade de Einstein! A Sociologia do Currículo sempre parecerá uma ameaça à identidade de alguns, mas um desafio emocionante para outros. Não surpreendentemente, isso coloca dificuldades que eles preferem evitar.

\section{Muito Obrigado.}

\section{Referências}

FORQUIN, J. C. Escola e cultura: as bases sociais e epistemológicas do conhecimento escolar. Porto Alegre: Artes Médicas, 1993.

MOREIRA, A. F. B.; SILVA, T. T. Sociologia e teoria crítica do currículo: uma introdução. In: MOREIRA, A. F. B.; SILVA, T. T. (orgs.). Currículo, cultura e sociedade. São Paulo: Cortez, 2002. p. 7-37.

SILVA, T. T. O que produz e o que reproduz em educação. Ensaios de Sociologia da Educação. Porto Alegre: Artes Médicas, 1992.

YOUNG, M. A propósito de uma sociologia crítica de educação. Revista Brasileira de Estudos Pedagógica, Brasília, v. 67, n. 157, p. 532-537, 1986. 
YOUNG, M. Currículo e democracia: lições de uma crítica à "nova sociologia da educação". Educação \& Realidade, Porto Alegre, v. 14, n. 1, p. 29-40, 1989.

YOUNG, M. (org.). Knowledge and control: new directions for the sociology of education. London: Collier Macmillan, 1971.

YOUNG, M. O futuro da educação em uma sociedade do conhecimento: o argumento radical em defesa de um currículo centrado em disciplinas. Revista Brasileira de Educação, Rio de Janeiro, v. 16, n. 48, 2011. https://doi.org/10.1590/S1413-24782011000300005

YOUNG, M. Para que servem as escolas? Educação \& Sociedade, Campinas, v. 28, n. 101, 2007. https://doi. org/10.1590/S0101-73302007000400002

\section{Sobre os Autores}

Marcelo Pinheiro Cigales é licenciado em Ciências Sociais pela Universidade Federal de Pelotas (UFPEL), doutor em Sociologia Política pela Universidade Federal de Santa Catarina (UFSC), professor adjunto do Departamento de Sociologia da Universidade de Brasília (UnB) e coordenador do Laboratório de Ensino de Sociologia Lélia Gonzalez, registrado no CNPQ (Sol/UnB). Pesquisa e orienta trabalhos sobre o Ensino de Sociologia e Sociologia da Educação.

Amurabi Pereira de Oliveira é licenciado e mestre em Ciências Sociais pela Universidade Federal de Campina Grande (UFCG) e doutor em Sociologia pela Universidade Federal de Pernambuco (UFPE), com estágio pós-doutoral pela Universidade Autônoma de Barcelona. Professor da Universidade Federal de Santa Catarina (UFSC) e pesquisador do CNPq. Atua principalmente nas áreas de Antropologia e Sociologia da Educação, Ensino de Ciências Sociais e História das Ciências Sociais.

Diego Greinert de Oliveira é licenciado, bacharel e mestre em Ciências Sociais pela Universidade Estadual de Londrina (UEL), doutorando em Sociologia pela Universidade Federal de Santa Catarina (UFSC) e bolsista Capes. Atualmente, pesquisa os processos de construção de políticas educacionais e curriculares, assim como o Ensino de Sociologia.

Recebido: 10 mar. 2020

Aprovado: 29 abr. 2020 